\begin{tabular}{|c|c|c|c|c|c|c|}
\hline Impact Factor: & $\begin{array}{l}\text { ISRA (India) } \\
\text { ISI (Dubai, UAE } \\
\text { GIF (Australia) } \\
\text { JIF }\end{array}$ & $\begin{array}{l}=1.344 \\
=0.829 \\
=0.564 \\
=1.500\end{array}$ & $\begin{array}{l}\text { SIS (USA) } \\
\text { PИНЦ (Russia } \\
\text { ESJI (KZ) } \\
\text { SJIF (Morocco }\end{array}$ & $\begin{array}{l}=0.912 \\
=0.207 \\
=4.102 \\
=\mathbf{2 . 0 3 1}\end{array}$ & $\begin{array}{l}\text { ICV (Poland) } \\
\text { PIF (India) } \\
\text { IBI (India) }\end{array}$ & $\begin{array}{l}=6.630 \\
=1.940 \\
=4.260\end{array}$ \\
\hline
\end{tabular}

\section{SOI: $1.1 /$ TAS DOI: $10.15863 /$ TAS International Scientific Journal Theoretical \& Applied Science}

p-ISSN: 2308-4944 (print) e-ISSN: 2409-0085 (online)

Year: $2018 \quad$ Issue: 02 Volume: 58

Published: $19.02 .2018 \quad$ http://T-Science.org

SECTION 2. Applied mathematics. Mathematical modeling.
Zhadra Kozhamkulova

Department «Automation and information technologies», Associate professor, Noncommercial joint-stock company

"Kazakh national agrarian university", Kazakhstan zhadra_555@mail.ru

Mukhit Maikotov

Department «Math and mathematical modeling», Master, Kazakh National Pedagogoical University named after Abai, Kazakhstan mukhit777@mail.ru

Bibinur Kirkizbayeva Department «Automation and information technologies», Associate professor, Noncommercial joint-stock company

"Kazakh national agrarian university", Kazakhstan bibinur_62@mail.ru

Zhumakyz Chingenzhinova

Department «Automation and information technologies», Master, Noncommercial joint-stock company "Kazakh national agrarian university", Kazakhstan zhumagiz@mail.ru

Gulzhan Sapieva Department «Automation and information technologies», Master, Noncommercial joint-stock company

"Kazakh national agrarian university", Kazakhstan sapieva@mail.ru

Venera Kerimbaeva

Master, Department « Information Technology», Almaty Technic University, Kazakhstan

kerimbayeva@mai.ru

\title{
EXTENSION METHOD FOR LOCATION PROBLEMS WITH DISCRETE OBJECTS
}

Abstract: In this paper, we propose an efficient algorithm for finding exact stable solutions to problems of optimal allocation of discrete objects in which the constraint matrix could be almost singular, and the basic parameters of the problem could be uncertain. In modeling parameter uncertainty, we consider commonly used distributions; such as normal, uniform, exponential, linear, gamma-distribution, geometric, and Poisson distributions.

Key words: Extension method, resource allocation problem, search algorithm.

Language: English

Citation: Kozhamkulova Z, Maikotov M, Kirkizbayeva B, Chingenzhinova Z, Sapieva G, Kerimbaeva V (2018) EXTENSION METHOD FOR LOCATION PROBLEMS WITH DISCRETE OBJECTS. ISJ Theoretical \& Applied Science, 02 (58): 64-69.

Soi: http://s-o-i.org/1.1/TAS-02-58-16 Doi: croskef https://dx.doi.org/10.15863/TAS.2018.02.58.16

\section{Introduction}

Modern design engineers often face problems of optimal placement of various objects such as lathes, hospitals, remote computer terminals, airports, computer programs, warehouses, displays, office spaces in administrative buildings, industrial plants, factories, fire brigades, banks, post offices, etc. The first attempts at rational location and layout of objects were made in the seventeenth century. However, only when the theory of operations research had developed, these problems became subjects of thorough and comprehensive studies. Since placement of objects often involves significant and irreversible material costs, the development of 


\begin{tabular}{|c|c|c|c|c|c|c|}
\hline Impact Factor: & $\begin{array}{l}\text { ISRA (India) } \\
\text { ISI (Dubai, UAE } \\
\text { GIF (Australia) } \\
\text { JIF }\end{array}$ & $\begin{array}{l}=1.344 \\
=0.829 \\
=0.564 \\
=1.500\end{array}$ & $\begin{array}{l}\text { SIS (USA) } \\
\text { PUHЦ (Russia) } \\
\text { ESJI (KZ) } \\
\text { SJIF (Morocco) }\end{array}$ & $\begin{array}{l}=0.912 \\
=0.207 \\
=4.102 \\
=\mathbf{2 . 0 3 1}\end{array}$ & $\begin{array}{l}\text { ICV (Poland) } \\
\text { PIF (India) } \\
\text { IBI (India) }\end{array}$ & $\begin{array}{l}=6.630 \\
=1.940 \\
=4.260\end{array}$ \\
\hline
\end{tabular}

apparatus and methods for optimal placement of objects is one of important areas of the optimization science.

Problems of allocating discrete objects are classified as problems of mixed-integer programming (MIP), which are NP-complex problems. Exact solution methods to such problems have exponential complexity bounds [1]. Over the past twenty years, the development of directed search methods such as the branch and bound method (BBM), and creation of sophisticated, mainly commercial, computer programs, addressed the need for solving MIP problems to some extent.

However, BBM is not suitable for large-scale problems. In recent years, a number of methods have been developed that improve BBM. For example, the method of nodal vectors (MNV) has been developing since 1998. For large size problems of high with at least 80 integer variables, the CPU time requirements for $\mathrm{MNV}$ are on average two to five times smaller than with BBM [2].

All these methods are effective only if the model of allocation of discrete resources is formulated correctly. In practice, many parameters are often determined approximately which leads to an incorrect formulation of "perturbed" optimization problems. The problem of finding solutions to illposed problems . In [4] a method was proposed that first finds the generating system from the original unperturbed optimization problem and then uses the characteristics of the generating system to assess perturbation effects in forming the optimal solution. Although this approach has a theoretical significance, its implementation requires large computing resources, moreover, the method produces only approximate solutions.

In $[5,6]$, an extension method is proposed that expands the set of feasible values for solution of the optimal resource allocation problem between parallel objects.

In [7] the extension method is generalized for a new class of problems with parallel random flows. In the proposed method, the solution of the original optimization problem is determined by a directed transition to the optimum from a point which corresponds to the solution of some auxiliary problem with an expanded set of feasible values. The computational procedure ensures the exact solution of the problem. In the article, the extension method is generalized to discrete allocation problems with uncertain parameters.

\section{A mathematical formulation of the problem}

Consider the following plant allocation problem. Given a finite set of locations where plants could be deployed and a customer list. Deployed plants produce a homogeneous product in unlimited quantities. The deployment costs for each plant; that is, the total production and transportation costs are minimized. Let us introduce the following notation.

$m$ - the number of possible deployment locations; $i$ is the index of the location (plant), $i \in$ $I=(1, \ldots, m)$;

$n$ - the number of customers, $j$ is the customer index, $j \in J=(1, \ldots, n)$;

$b_{j}$ - the $j$-customer's need for the product; for simplicity, we take $b_{j}=1$ for all $j$;

$c_{i}$ - the cost of placing a plant in location $i$;

$c_{i j}$ - the cost of meeting the demand of customer $j$ by the plant $i$ (including the costs of production and transportation);

$y_{i j}$ - the part of the whole product to be delivered to customer $j$ from plant $i$;

$x_{i}=\left\{\begin{array}{l}1, \text { if there is a plant in location } i, \\ 0, \text { otherwise. }\end{array}\right.$

The mathematical formulation of the problem is as follows (see [2]):

$$
F(x, y)=\sum_{i=1}^{m} c_{i} x_{i}+\sum_{i=1}^{m} \sum_{j=1}^{n} c_{i j} y_{i j} \rightarrow \min
$$

subject to the following constraints:

$$
\begin{aligned}
& \sum y_{i j} \leq x_{i}, i=\overline{1, m} \\
& \sum y_{i, j}=1, j=\overline{1, n} \\
& x_{i}=\{0,1\}, \quad y_{i j} \geq 0, i=\overline{1, m}, \quad j=\overline{1, n} .
\end{aligned}
$$

For fixed values of $x_{i}$, the allocation problem takes the following form:

$$
F=\sum_{i=1}^{m} \sum_{j=1}^{n} c_{i j} y_{i j} \rightarrow \min
$$

Subject to the following constraints

$$
\begin{aligned}
& \sum_{j=1}^{n} y_{i j} \leq 1, i=\overline{1, m} \\
& \sum_{i=1}^{m} y_{i j}=1, j=\overline{1, n} . \\
& y_{i j} \in[0,1], i=\overline{1, m}, \quad j=\overline{1, n}
\end{aligned}
$$

In accordance with the extension method [5], we introduce an auxiliary extended problem, obtained from the original problem by discarding the constraints of the form (6): 


\begin{tabular}{|c|c|c|c|c|c|c|}
\hline Impact Factor: & $\begin{array}{l}\text { ISRA (India) } \\
\text { ISI (Dubai, UAE } \\
\text { GIF (Australia) } \\
\text { JIF }\end{array}$ & $\begin{array}{l}=1.344 \\
=0.829 \\
=0.564 \\
=1.500\end{array}$ & $\begin{array}{l}\text { SIS (USA) } \\
\text { PИНЦ (Russia) } \\
\text { ESJI (KZ) } \\
\text { SJIF (Morocco) }\end{array}$ & $\begin{array}{l}=0.912 \\
=0.207 \\
=4.102 \\
=\mathbf{2 . 0 3 1}\end{array}$ & $\begin{array}{l}\text { ICV (Poland) } \\
\text { PIF (India) } \\
\text { IBI (India) }\end{array}$ & $\begin{array}{l}=6.630 \\
=1.940 \\
=\mathbf{4 . 2 6 0}\end{array}$ \\
\hline
\end{tabular}

$$
F=\sum_{i=1}^{m} \sum_{j=1}^{n} c_{i j} y_{i j} \rightarrow \min
$$

subject to the following constraints:

$$
\begin{aligned}
& \sum_{i=1}^{m} y_{i j}=1, j=\overline{1, n}, \\
& y_{i j} \in[0,1], i=\overline{1, m}, j=\overline{1, n}
\end{aligned}
$$

Let us establish a relation between sets $\mathrm{Y}$ and $\mathrm{Y}^{\mathrm{p}}$, feasible solution sets for the original and extended problems, respectively. Suppose that the original problem has a unique solution.

Proposition 1. The set of feasible solutions $Y$ of the original problem (5)-(8) is a subset of the set of feasible solutions of the extended problem (9)(11), i.e. $\mathrm{Y} \subset \mathrm{Y}^{\mathrm{p}}$ ".

(See $[5,8,9])$

However, their optimal solutions coincide if the conditions of the following statement are satisfied (see $[5,9])$

Proposition 2. The optimal solution of the original problem coincides with the optimal solution of the extended problem only if:

1) the sets of admissible solutions of these problems are equivalent;

2) the optimal solution of the extended problem belongs to the set $Y$, i.e. $y^{p^{*}} \in Y$.

This statement follows from the fact that the objective functions of the extended and of the original problems are identical.

The equivalence of the feasible solution sets of these problems implies the equivalence of the problems themselves and, consequently, of their optimal solutions. Since $F^{p}=\inf F$, the constraint (6) of the original problem is not binding.

If the solution of the expanded problem (9)-(11) does not belong to the set $\mathrm{Y}$, i.e. $\mathrm{y}^{\mathrm{p}} \square \mathrm{Y}$, then sup $\mathrm{F}>\mathrm{F}^{\mathrm{p}}$, and one can use the following approach to search for optimal solutions of the original problem.

$\square$ Use the auxiliary problem (9)-(11) for establishing effective limits of the original problem. This reduces significantly the dimension of the original problem, and, hence, reduces computational errors.

Use the solution $\mathrm{y}^{\mathrm{p}}$ of the extended problem for the directed transition to the solution of the original problem.

For later use, let us also define a set of the following sub-problems of the problem (9)-(11):

$$
\begin{aligned}
& F_{j}=\sum_{j=1}^{m} c_{i j} y_{i j} \rightarrow \min , \quad j=\overline{1, n} \\
& \sum_{i=1}^{m} y_{i j}=1, \\
& y_{i, j} \in[0,1], \quad i=\overline{1, m}, \quad j=\overline{1, n}
\end{aligned}
$$

The essence of the extension method is that the solution of the original problem (5) - (8) is obtained by the directed transition to its optimal solution from the point corresponding to the solution of the extended problem (9) - (11).

Since the value of the objective function of the extended problem in its optimum point is a lower bound on possible values of the objective function of the original problem, any transition from the point corresponding to the solution of the problem (9)-(11) to another point $y \square Y$ will increase the value of the objective function. In other words, this transition will mean a descent from $-\mathrm{F}^{\mathrm{p}}$ to a different value of the objective function. The resulting solution is optimal if the descent in this direction leads to the smallest change in the objective function value compared with any other direction.

We now outline the following general scheme for solving the problem of locating objects by the extension problem (5)-(6) and (9)-(10).

1. Solve the extended problem (9)-(11).

2. Verify if the obtained solution is feasible with respect to the constraints (6) of the original problem. If the solution is feasible, then it is optimal; otherwise, go to Step 3.

3. Select a search direction and a descent step.

4. Find a new approximation to the solution.

Solving the plant allocation problem with the extension method

Suppose that the solution $y^{p}$ of the extended problem does not satisfy all the constraints of the original problem, and it is necessary to find a transition to a new approximation

$$
\mathrm{y}=\mathrm{y}^{\mathrm{p}}+\mathrm{h} \text {. }
$$

The descent step $\mathrm{h}$ is calculated according to the following scheme:

$$
\left\{\begin{array}{l}
-1, \text { beginning of descent, } \\
1, \text { end of descent, } \\
0, \text { otherwise. }
\end{array}\right.
$$

Using the results in [9], we state the following lemma on the choice of the descent direction in discrete resource allocation problems.

Lemma. The point $y=y^{p}+h j^{*} k l$ is a solution to the original problem of the plant allocation problem (5)-(8) if and only if the parameters $j^{*}, k$ and,$l$ are satisfy the condition 


\begin{tabular}{l|lr|ll|ll} 
& ISRA (India) & $=\mathbf{1 . 3 4 4}$ & SIS (USA) & $=\mathbf{0 . 9 1 2}$ & ICV (Poland) & $=\mathbf{6 . 6 3 0}$ \\
Impact Factor: & ISI (Dubai, UAE) $=\mathbf{0 . 8 2 9}$ & PUHL (Russia) $=\mathbf{0 . 2 0 7}$ & PIF (India) & $=\mathbf{1 . 9 4 0}$ \\
& GIF (Australia) & $=\mathbf{0 . 5 6 4}$ & ESJI (KZ) & $=4.102$ & IBI (India) & $=\mathbf{4 . 2 6 0}$ \\
& JIF & $=\mathbf{1 . 5 0 0}$ & SJIF (Morocco) $=\mathbf{2 . 0 3 1}$ & & \\
\hline
\end{tabular}

$$
\left(j^{*}, k, l\right)=\max \left\{\frac{\begin{array}{c}
{\left[\min \left(c_{j l}-c_{j k}^{p}\right), \quad j=\overline{1, n}\right.} \\
(k, l) \in N_{h}^{j}
\end{array}}{c_{j^{*} k}}\right\},
$$

where $J_{i}$ is a set of indexes of the sub-problems (12)(14), the extends solution of which must be changed.

Based on the general solution procedure and the preceding lemma, we formulate the following algorithm for solving the original problem (5)-(8).

Step 1. Find the solution $\mathrm{y}^{\mathrm{p}}$ of the extended problem (9)-(11).

Step 2. Verify if the solution satisfies constraints (6). If it does, go to Step 8.

Step 3. Find the set of indexes of restrictions (6) which the solution $\mathrm{y}^{\mathrm{p}}$

$$
\left\{k \mid s_{i}=\sum y_{i j}>1, \quad i=\overline{1, m}\right\}
$$

does not satisfy.

Step 4. Find possible descent directions from the conditions

$$
\begin{aligned}
& N_{b}=\bigcup_{j-1}^{n} N_{b}^{j}, \\
& N_{b}^{j}=\left\{(k, l) \mid \min \left[\left(c_{j l}-c_{j k}^{p}\right) \mid s_{i}=0\right\}\right.
\end{aligned}
$$

Step 5. Find a set of indexes of sub-problems (12)-(14) that require the transition to a new solution

$$
J_{n}=\left\{j \mid \min \left(c_{j l}-c_{j k}^{p}\right)\right\}
$$

If this condition identifies only one subproblem (12)-(14), go to Step 7.

Step 6. Using the following relation, find the index $j^{*}$ of a sub-problem which must be changed first to make the transition to a new solution:

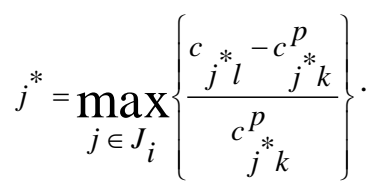

Step 7. Transition to a new solution of the $\mathrm{j}$-th sub-problem (12)-(14).

$$
y_{i j}=y_{i j}^{p}+h
$$

where

$$
h=\left\{\begin{array}{l}
-1, \text { if } i=l, \\
1, \text { if } i=k, \\
0 \text { in other cases. }
\end{array}\right.
$$

Compute $\mathrm{s}_{\mathrm{i}} \mathrm{i}=1, \mathrm{~m}$. Go to Step 2 .

Step 8. The resulting solution is optimal. Compute F.

\section{Simulating the plant allocation problem} with random parameter values

To simulate the plant allocation problem with uncertainties in the parameters $\mathrm{m}, \mathrm{n}, \mathrm{c}_{\mathrm{ij}}$, we use the methods given in [8]. For example, suppose that the cost of production and transportation $c_{i j}$ is a continuous random variable $\square$ with the density function $\mathrm{f}(\mathrm{x})>0$.

To simulate the discrete random variable $\mathrm{m}$ and $\mathrm{n}$, we assume that their possible realizations $\mathrm{x}_{\mathrm{j}}$ are distributed in the matrix

$$
\left(\begin{array}{llll}
x_{1} & x_{2} & \ldots & x_{m} \\
p_{1} & p_{2} & \ldots & p_{m}
\end{array}\right)
$$

An algorithm for solving the problem of locating objects with random parameters

To solve the original problem (5) - (8) with uncertain parameters, we formulate the following generalized solution algorithm which is based on the general solution procedure of the extension method and covers the well-known theoretical distributions such as normal, uniform, exponential, linear, geometric, the Poisson, and gamma distributions.

Step 1. Input parameters defining distributions of $\mathrm{c}_{\mathrm{ij}}$.

Step 2. Draw values of $\mathrm{z}$.

Step 3. Choose distributions for $m$ and $n$, and ensure the following conditions:

$$
\begin{aligned}
& P\{m=k\}=\frac{\lambda^{k}}{k !} e^{-\lambda}, P\{n=k\}=\frac{\lambda^{k}}{k !} e^{-\lambda}, \\
& P\{m=k\}=p^{*}(1-p)^{k-1}=p_{k}, \\
& P\{n=k\}=p^{*}(1-p)^{k-1}=p_{k},
\end{aligned}
$$

Step 4. Depending on the results in Step3, compute the values of $\mathrm{m}$ and $\mathrm{n}$ according to the formulas: $m=n=S$, where $S$ is the number of events happening with probability $\mathrm{p}$;

$$
\begin{aligned}
& x_{j}=\text { Integer }\left[\frac{\ln Z}{\ln (1-p)}\right]+1, \\
& x_{j}=\text { Integer }\left[\frac{\ln Z}{\ln (1-p)}\right]+1,
\end{aligned}
$$

where Integer [] stands for the integer part of the termin brackets.

Step 5. Choose the distributions of $c_{\mathrm{ij}}$. Verify the following conditions:

Step 6. Depending on the results in Step 5, compute the values of $\mathrm{c}_{\mathrm{ij}}$ using the formulas 


\begin{tabular}{l|lr|ll|ll} 
& ISRA (India) & $=\mathbf{1 . 3 4 4}$ & SIS (USA) & $=\mathbf{0 . 9 1 2}$ & ICV (Poland) & $=\mathbf{6 . 6 3 0}$ \\
Impact Factor: & ISI (Dubai, UAE) $=\mathbf{0 . 8 2 9}$ & PUHL (Russia) $=\mathbf{0 . 2 0 7}$ & PIF (India) & $=\mathbf{1 . 9 4 0}$ \\
& GIF (Australia) & $=\mathbf{0 . 5 6 4}$ & ESJI (KZ) & $=4.102$ & IBI (India) & $=\mathbf{4 . 2 6 0}$ \\
& JIF & $=\mathbf{1 . 5 0 0}$ & SJIF (Morocco) $=\mathbf{2 . 0 3 1}$ & & \\
\hline
\end{tabular}

$$
\begin{aligned}
& c_{i j}=m_{x}+\sigma_{x}\left(\sum_{l=1}^{12} z_{l}-6\right), \\
& c_{i j}=\min +z(\max -\min ), c_{i j}=-\frac{1}{\lambda} \ln z, \\
& c_{i j}=\frac{2}{\lambda}(1-\sqrt{z}), \\
& c_{i j}=-\frac{1}{\alpha} \ln \left(z_{1} * z_{2} * \ldots * z_{k}\right), \\
& i=\overline{1, m}, j=\overline{1, n} .
\end{aligned}
$$

Step 7. For given $\mathrm{m}, \mathrm{n}$, and $\mathrm{c}_{\mathrm{ij}}$ use the extension method described in Section 2 to find the solution of problem (5)-(8).

$$
\begin{aligned}
& \text { Application } \\
& f(x)=\frac{1}{\sigma_{x} \sqrt{2 \pi}} e^{-\frac{\left(x-m_{x}\right)^{2}}{2 \sigma_{x}^{2}},} \\
& f(x)=\frac{1}{\max -\min }, x \in[\min , \max ], \\
& f(x)=\lambda e^{-\lambda x}, x \geq 0, \quad f(x)=\lambda\left(1-\frac{\lambda}{2} x\right), \\
& f(x)=\alpha^{k}[(k-1) !]^{-1} x^{(k-1)} e^{-\alpha x}
\end{aligned}
$$

The results of this study were used to develop a control system for one of the largest metal producers in the world, the Ust-Kamenogorsk Lead and Zinc Plant which is structured into an extensive network of sequential and parallel processes [10]. The designed system controlled the sulfur acid production process which had five different sequential production phases taking place in dry filters, drying towers, wet filters, absorbers and contact devices. Each phase utilized from 4 to 10 parallel units with nearly homogeneity of the parallel processes. The resulting constraint matrix of the formulated model is nearly singular, and it has a high degree of multi-co-linearity (see [11]), which causes solution instability and a low degree precision of obtained solutions. The application of the extension method with uncertain parameters gave a solution with the error margin of less than $0.05 \%$. Traditional optimization methods have $15 \%$ error margins, and they gave solutions that were unacceptable to the plant administration. Thus, the practical implementation of the method demonstrated that, in contrast to other traditional optimization methods, the proposed procedure for solving optimization problems of object placement allows to find accurate and stable solutions even when the constraint matrix is close to being singular.

\section{Conclusions}

The results of this study were used to develop a control system for one of the largest metal producers in the world, the Ust-Kamenogorsk Lead and $\mathrm{Z}$ in Plant, which is structured into an extensive network of sequential and parallel processes [10]. The designed system controlled the sulfur acid production process, which had five different sequential production phases, taking place in dry filters, drying towers, wet filters, absorbers and contact devices. Each phase utilized from 4 to 10 parallel units, with nearly homogeneity of the parallel processes, the resulting constraint matrix of the formulated model is nearly singular, and it has a high degree of multi-colinearity. (See [11], which causes solution instability and a low degree precision of obtained solutions. The application of the optimal method with uncertain parameters a solution with the error margin of less than 5\%. Traditional optimal methods have $15 \%$ error margins and they gave solutions that were unacceptable to the plant administration. Thus, the practical implementation of the method demonstrated that in contrast to other traditional optimization methods, the proposed procedure for solving optimization problems of object placement allows to find accurate and stable solutions, even when the constraint matrix is close to being singular.

\section{References:}

1. Zhagal D., Lebedev S.S. (1988) Integer programming problems with fuzzy coefficients and the right side, Economics and Mathematical Methods, V. 24, Vol. 3, 1988, p. 518-527 (in Russian)

2. Sedova S.V., Lebedev S.S. (1999) Solution of a location problem using the nodal vectors of resolving multipliers, Economics and Mathematical Methods, V. 35, Vol. 3, 1999, p. 116-121 (In Russian).

3. Tikhonov A.N., Arsenin V.Y. (1986) Methods for solving ill-posed problems, Moscow, Science, 1986 (In Russian). 
\begin{tabular}{l|lr|ll|ll} 
& ISRA (India) & $=\mathbf{1 . 3 4 4}$ & SIS (USA) & $=\mathbf{0 . 9 1 2}$ & ICV (Poland) & $=\mathbf{6 . 6 3 0}$ \\
Impact Factor: & ISI (Dubai, UAE) $=\mathbf{0 . 8 2 9}$ & PUHЦ (Russia) $=\mathbf{0 . 2 0 7}$ & PIF (India) & $=\mathbf{1 . 9 4 0}$ \\
& GIF (Australia) & $=\mathbf{0 . 5 6 4}$ & ESJI (KZ) & $=4.102$ & IBI (India) & $=\mathbf{4 . 2 6 0}$ \\
& JIF & $=\mathbf{1 . 5 0 0}$ & SJIF (Morocco) & $=\mathbf{2 . 0 3 1}$ & & \\
\hline
\end{tabular}

4. Pervozvanskiy A.A. (1979) Optimization of systems with weak coupling, Systems Science, V. 1-2, Vol. 2, 1979, p. 23-32 (In Russian).

5. Shukaev D.N. (1998) Optimization of resource allocation processes in parallel structure systems, Proceedings of the International Scientific and Technical conference FEIIC, Almaty, 1999, p. 185-192 (In Russian).

6. Shukaev D.N., Tazhibayeva A.K. (1998) Simulation and optimization of resource allocation processes in systems with a parallel structure, Presentation at the International Scientific-Technical Conference “ Modeling and study of complex systems," Moscow, 1998, p. 144-150 (in Russian).

7. Ermakov A.S., Shukaev D.N., Kim Y.R. (2002) Distribution of parallel streas from the resource,
Herald of Kaz. NTU, 2002, No. 3, p. 18-22 (in Russian).

8. Shukaev D.N. (2004) Computer Similation, Almaty, Kaz. NTU, 2004 (in Russian).

9. Esbatyrov T.E., Shukaev D.N., Hisar B.D. (1988) Distribution of loads in parallel systems by means of expansion, Mathematical, algorithmic and technical support of DCS, Tashkent, 1988, p. 153-160 (in Russian).

10. Shukaev D.N., Dzhaksybaeva A.K. (2004) Allocation of resources in parallel systems simulation model and analysis, Collection of scientific works, Moscow Academy of Instrument Engineering and Informatics, "Mathematical modeling and control in complex systems," Vol. 4, Moscow, 2004, p. 161-166 (in Russian). 